\title{
Superionic iron-hydrogen alloys in Earth's inner core
}

\author{
WENZHONG WANG ${ }^{1,2}$, YUNGUO LI ${ }^{3}$, JOHN \\ BRODHOLT $^{1}$, LIDUNKA VOČADLO ${ }^{1}$, MICHAEL J. \\ WALTER $^{4}$ AND ZHONGQING WU ${ }^{2}$
}

${ }^{1}$ University College London

${ }^{2}$ University of Science and Technology of China

${ }^{3}$ School of Earth and Space Sciences, University of Science and Technology of China

${ }^{4}$ Carnegie Institution for Science

Presenting Author: wenzhong.wang@ucl.ac.uk

Earth's core plays a fundamental role in the evolution and habitability of our planet. It is responsible for the geodynamo and records important information regarding the history of Earth's accretion. Information about Earth's core is obtained from seismology and chemical models must be consistent with seismic observations. Seismic and mineralogical models suggest that the Earth's core is predominantly composed of iron (or iron-nickel alloy) with several percent of light elements, such as silicon ( $\mathrm{Si}$ ), sulfur $(\mathrm{S})$, carbon $(\mathrm{C})$, oxygen $(\mathrm{O})$, and hydrogen $(\mathrm{H})$ [1]. One of the most intriguing characteristics is that Earth's inner core transmits shear waves at anomalously low velocity. Although some candidates, such as iron carbide and some ternary $h c p-\mathrm{Fe}$ Si-C alloys, were proposed to explain the seismic observations, $\mathrm{C}$ is unlikely a primary element in the inner core and others without $\mathrm{C}$ cannot explain the low $\mathrm{V}_{\mathrm{S}}$ and the density of the inner core simultaneously.

The core is potentially the largest reservoir of $\mathrm{H}$ in the Earth's interior as $\mathrm{H}$ prefers to partition into the iron liquid under coreformation conditions [2]. Here we investigate the elastic properties of iron-hydrogen and iron-silicon-hydrogen alloys using $a b$ initio molecular dynamic simulations. We find that these H-bearing alloys maintain a superionic state under innercore conditions and that their shear moduli exhibit a strong shear softening due to the superionic effect, with a corresponding reduction in $\mathrm{V}_{\mathrm{S}}$. The $h c p$-iron-silicon-hydrogen alloys can explain the observed density, $\mathrm{V}_{\mathrm{P}}, \mathrm{V}_{\mathrm{S}}$, and Poisson's ratio of the inner core simultaneously. Our results strongly indicate that hydrogen is a fundamental light element in the Earth's core.

[1] J.-P. Poirier, Light elements in the Earth's outer core: A critical review. Phys. Earth Planet. Inter. 85, 319-337 (1994).

[2] Y. Li, L. Vočadlo, T. Sun, J. P. Brodholt, The Earth's core as a reservoir of water. Nat. Geosci. 13, 453-458 (2020). 